\title{
Humidity Sensitive Properties of Restructural Films Prepared from Polymer Latex with Carboxylic Acid Functional Groups
}

\author{
Chia-Fen $\mathrm{LEE}^{\dagger}$ and Wen-Yen CHIU ${ }^{*}$ \\ Department of Cosmetic Science, Chia Nan College of Pharmacy and Science, Tainan, Taiwan, R. O.C. \\ ${ }^{*}$ Department of Chemical Engineering, National Taiwan University, Taipei, Taiwan, R. O.C.
}

(Received May 10, 1999)

\begin{abstract}
The polymer latex of poly(butyl acrylate(BA)-acrylic acid(AA)) was synthesized by soapless seeded emulsion polymerization or soapless emulsion copolymerization. The morphology of the composite polymer latex synthesized by soapless seeded emulsion polymerization was core-shell structure. The humidity-sensitive polymer films were made by the melting of the polymer latex at $68^{\circ} \mathrm{C}$ followed by chemical modification with aqueous solution of $\mathrm{NaOH}$. The glass transition temperature $\left(T_{\mathrm{g}}\right)$ of poly(butyl acrylate) (PBA) is below room temperature $\left(-54^{\circ} \mathrm{C}\right)$, so PBA has flexible behavior at the room temperature. The humidity-sensitive properties of the flexible polymer films were investigated. The core-shell polymer latex with either linear core or crosslinked core was synthesized. The polymer latex that had the crosslinked core was melted to form polymer films with crosslinked domains. The polymer latex that had the linear core was melted to form the polymer films with linear structure. It is confirmed that polymer films with crosslinked domains had larger humidity sensitivity and less hysteresis than polymer films with linear structure. The effect of multiple use on the humidity sensitivity of the polymer films with crosslinked domains was insignificant. For polymer films with crosslinked structure or poor flexibility, the degree of humidity sensitivity increased with temperature. The humidity sensitivity may decrease with increase of temperature for flexible films.
\end{abstract}

KEY WORDS Core-Shell Polymer Latex / Butyl Acrylate / Acrylic Acid / Flexible Film / Humidity Sensitive Property /

The humidity sensor is increasingly important in electronic control system. The conventional material of the humidity sensor is ceramics. In recent years, many humidity sensors have been investigated and placed on the market. ${ }^{1,2}$ The polymer materials have attracted many interests and research ${ }^{3-14}$ due to the fact that they do not require high-temperature processing and heat cleaning. Easy processing, low cost and good chemical stability are advantages of the polymer materials. In many polymer materials, the polyelectrolyte is the most advantageous materials to develop as the humidity sensor. The change of impedance of the polyelectrolyte is significant during absorption and desorption of water molecules. The first polymer humidity sensor was made by the method of using the $\mathrm{LiCl}$ dispersed in the hydrophilic poly(vinyl acetate). ${ }^{15}$ Afterward, many hydrophilic polymers were developed to be the humidity sensitive polymer materials. ${ }^{3-14}$ But the major disadvantage of hydrophilic polymer materials is that the hydrophilic polymer materials have poor water resistivity. So that the structure of polymer materials is disrupted by water easily.

Sakai et al. ${ }^{12}$ proposed three methods to improve the water resistivity of polymers : (1) crosslinking the polyelectrolyte (2) copolymerization with the hydrophobic polymer, and (3) graft copolymerization. Sakai et al. ${ }^{16}$ introduced the 2-hydroxy-3-methacryloxypropyltrimethyl ammonium chloride (HMPTAC) polymer film with interpenetrating polymer network (IPN) structure. They pointed out that the polymer films with the IPN structure have better water resistivity than the crosslinked structure.

Our previous works investigated the humidity sensitive properties of the polymer films prepared by the

\footnotetext{
${ }^{\dagger}$ To whom correspondence should be addressed.
}

melting of the poly(methyl methacrylate)-poly(methacrylic acid) (PMMA-PMAA) ${ }^{17}$ or poly(methyl methacrylate)-poly(acrylic acid) (PMMA-PAA) composite polymer latex. The glass transition temperature $\left(T_{\mathrm{g}}\right)$ of PMMA-PMAA and PMMA-PAA were about $130.1^{\circ} \mathrm{C}$ and $122.5^{\circ} \mathrm{C}$ respectively. Because $T_{\mathrm{g}}$ was far above room temperature, the polymer chains of these polymer films exhibited not so active segment motion around room temperature and flexibility appeared poor. Low toughness, low flexibility and poor film formation are the disadvantages of these rigid polymer films, which have poor flexibility. $T_{\mathrm{g}}$ of poly(butyl acrylate) (PBA) was about $-54^{\circ} \mathrm{C}$, far below room temperature, so that the polymer chains of PBA exhibited active segment motion around room temperature and showed flexible behavior. In order to improve the flexible behavior of the polymer films, butyl acrylate (BA) monomer was used, instead of methyl methacrylate (MMA) monomer, to prepare the PBA-PAA composite polymer latex that had $T_{\mathrm{g}}$ of about $-34.8^{\circ} \mathrm{C}$. Flexible PBA-PAA polymer films were made by melting the PBA-PAA composite latex.

The present report investigates the humidity sensitive properties of the polymer films prepared by melting the PBA-PAA polymer latex synthesized by soapless seeded emulsion polymerization ${ }^{18,19}$ or soapless emulsion copolymerization.

\section{EXPERIMENTAL}

\section{Materials}

BA and acrylic acid (AA) were distilled under nitrogen atmosphere and reduced pressure prior to polymerization. Other materials were analytical grade and used without further purification. Distilled and deionized water was used throughout the work. 


\section{Ingredients and Conditions for Polymerization}

Soapless seeded emulsion polymerization reactions were two stages. In the first stage, PBA seed latex was synthesized by soapless emulsion polymerization, the reaction was carried out at $80^{\circ} \mathrm{C}$ for $1 \mathrm{~h}$, and the stirring rate was controlled at $300 \mathrm{rpm}$. After the first stage was complete, the seed latex, BA and AA were added into a 1 -liter reactor. The reaction system was heated to the reaction temperature $\left(80^{\circ} \mathrm{C}\right)$, and the stirring rate was controlled at $300 \mathrm{rpm}$ with the addition of $\mathrm{K}_{2} \mathrm{~S}_{2} \mathrm{O}_{8}$. The reaction of the second stage began.

In the emulsion copolymerization, $\mathrm{K}_{2} \mathrm{~S}_{2} \mathrm{O}_{8}$ was used as initiator. The PBA-PAA copolymer latex was synthesized via soapless emulsion polymerization. The reaction was carried out at $80^{\circ} \mathrm{C}$. for $1 \mathrm{~h}$. The stirring rate was controlled at $300 \mathrm{rpm}$.

\section{Morphology}

The polymer films prepared by melting the polymer latex were ultramicrotomed to sections about $900 \AA$ thick and stained with $\mathrm{CsOH}$. The stained sections were observed by transmission electron microscopy (TEM) (Model : Hitachi H-600). In the TEM photograph, the PBA phase was light, and the PAA phase was dark.

\section{Coating and Chemical Modification}

The latex was dip-coated on the sintered alumina substrate with a pair of interdigitated silver-palladium (Ag$\mathrm{Pd}$ ) electrodes, and then put in the oven at $60^{\circ} \mathrm{C}$ for $68 \mathrm{~h}$. The latex was melted to form the polymer film that coated the surface of alumina substrate, and then the polymer film was chemical modified with $1 \mathrm{~N} \mathrm{NaOH}$ followed by repeated water rinsing. Finally it was dried at $50^{\circ} \mathrm{C}$ for $24 \mathrm{~h}$

\section{Measurement of Impedance at Various Relative Humidities}

A fabricated humidity sensor was placed in a chamber where the temperature and relative humidity were controlled. The impedance of the sensor at various humidities was measured with an impedance meter (Gen Rad $1698 \mathrm{M})$ at frequency of $1 \mathrm{kHz}$.

\section{Hysteresis}

The impedance of the sensors was measured at various humidities, changing from $90 \% \mathrm{RH}$ (Relative $\mathrm{Hu}$ midity) to $50 \% \mathrm{RH}$ and then back to $90 \% \mathrm{RH}$.

\section{Temperature Effect on the Humidity Sensitivity of Polymer Film}

The impedance of the polymer films at various humidities (90\% $\mathrm{RH}$ to $50 \% \mathrm{RH}$ ) was measured at different temperatures (i.e., $28^{\circ} \mathrm{C}, 40^{\circ} \mathrm{C}$, and $60^{\circ} \mathrm{C}$ ).

\section{RESULTS AND DISCUSSION}

According to our previous works, ${ }^{19-22}$ the morphology of the polymer latex synthesized by soapless seeded emulsion polymerization was core-shell structure. In this work, the PBA-PAA composite polymer latex was synthesized by soapless seeded emulsion polymerization. Either linear or crosslinking PBA particles were synthesized to be the seed latex, and BA and AA monomers were polymerized in the present of PBA seed latex to form the core-shell composite polymer latex. The PBA was the core and the $\mathrm{P}(\mathrm{BA}-\mathrm{AA})$ copolymer was the shell. The core--shell PBA-PAA composite latex with a linear PBA core and $\mathrm{P}(\mathrm{BA}-\mathrm{AA})$ copolymer shell was indicated as $\mathrm{PBA} / \mathrm{P}(\mathrm{BA}-\mathrm{AA})$, and the composite latex with crosslinked PBA core and $\mathrm{P}(\mathrm{BA}-\mathrm{AA})$ copolymer shell was indicated as $\mathrm{PBA}(\mathrm{XL}) / \mathrm{P}(\mathrm{BA}-\mathrm{AA})$. Most of the carboxylic acid functional groups $(-\mathrm{COOH})$ of $\mathrm{AA}$ were located on the surface of latex particles. The P(BA-AA) copolymer latex was synthesized by soapless emulsion copolymerization. The core-shell polymer or copolymer latex was used to prepare the polymer films and then the polymer films were chemical modification by $\mathrm{NaOH}$. When water molecular adsorbed on the polymer film, the $\mathrm{Na}^{+}$ion dissociation and played the role as charge transport carrier. An increase of water adsorption may increase the degree of $\mathrm{Na}^{+}$ion dissociation and increase the ionic conductivity. So, that the polymer film had the humidity-sensitive property. We could evaluate the humidity response characteristics of the polymer films from the impedance versus relative humidity plots.

\section{Morphology}

The morphology of vertical sections of the polymer film prepared by melting the $\mathrm{PBA} / \mathrm{P}(\mathrm{BA}-\mathrm{AA})$ core-shell composite latex is shown in Figure 1a. The morphology appeared that the PAA domains distributed around the PBA domains, so that most of the surface of polymer film was covered by the PAA domain, and most of the hydrophilic carboxylic acid groups were located on the surface of polymer film. The morphology of vertical section of the polymer film prepared from the $\mathrm{PBA}(\mathrm{XL}) / \mathrm{P}(\mathrm{BA}-\mathrm{AA})$ core -shell composite latex is shown as Figure $1 \mathrm{~b}$. The morphology of the vertical section of the polymer film prepared from the $\mathrm{PBA}(\mathrm{XL}) / \mathrm{P}(\mathrm{BA}-\mathrm{AA})$ core-shell composite latex is the same as that prepared from the PBA/P $\left(\mathrm{BA}^{-}\right.$ AA). The morphology of vertical section of the polymer film prepared from the PBA-PAA copolymer latex showed that most of the PAA domains coagulated and were located at the inner zone of PBA domains, as shown in Figure 1c. Only a little PAA was distributed on the surface of polymer film, and only a little of the hydrophilic carboxylic acid groups was located on the surface of polymer film.

\section{Effects of Structure of Latex Particles}

The relation between relative humidity and impedance of polymer films prepared from latex particles with different structures is shown in Figure 2. The humidity sensitivity of the polymer films was the impedance ratio at the relative humidities of $50 \%$ and $90 \%(50 \% \mathrm{RH} / 90 \%$ $\mathrm{RH})$. The results for humidity sensitivity of polymer films are shown in Table I. The impedance ratio of $50 \%$ $\mathrm{RH} / 90 \% \mathrm{RH}$ of polymer films prepared by melting the polymer latex with the core-shell structure was larger than that produced by melting the copolymer latex. The former had better humidity sensitivity than the latter, since the hydrophilic carboxylic acid functional groups $(-\mathrm{COOH})$ of the polymers produced by copolymerization often merged inside the latex particles due to twisting and coiling of polymer chains. Hydrophilic carboxylic acid functional groups of the polymers by seeded polymerization were mostly located on the surface of latex particles. After the core- ${ }^{-}$shell polymer latex was dried and 


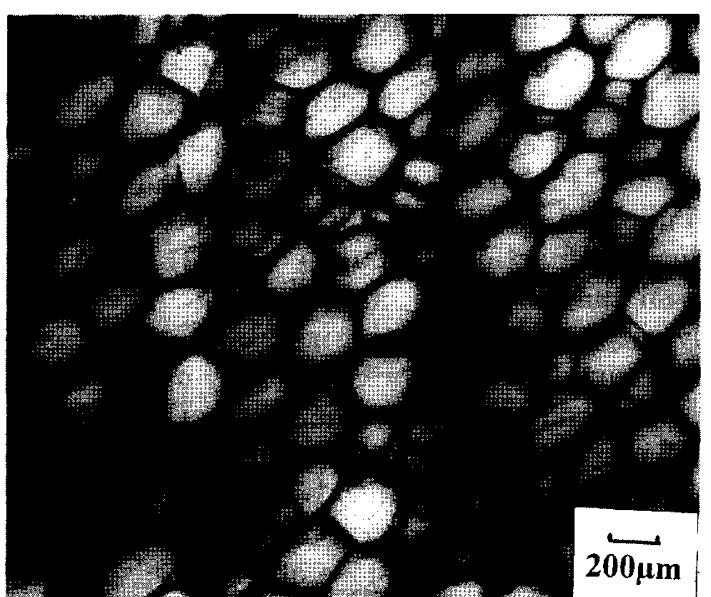

(a)

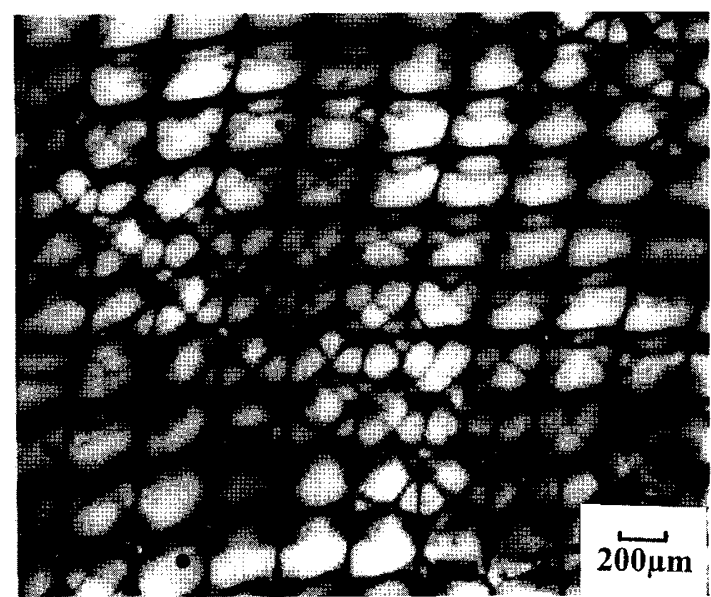

(b)

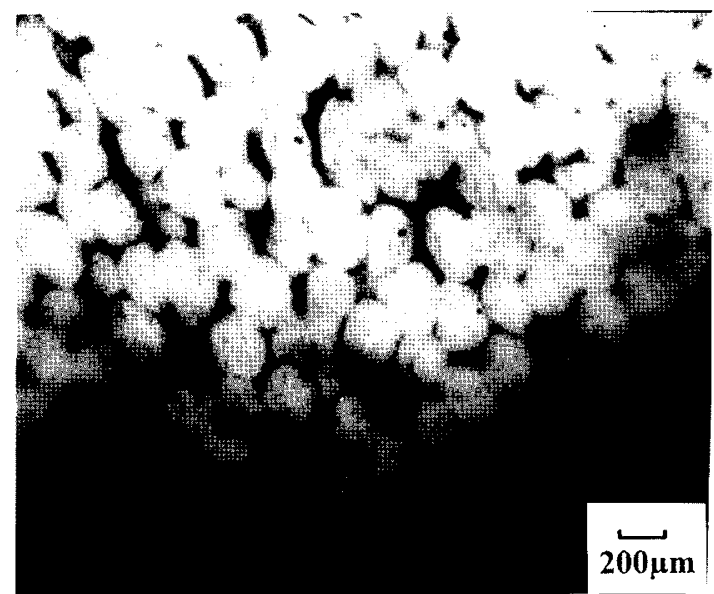

(c)

Figure 1. TEM photographs of vertical sections of polymer films melted from latex polymers at $60^{\circ} \mathrm{C}$ for $68 \mathrm{~h}$. (a) Morphology of polymer film that was prepared from PBA/P(BA-AA) core-shell composite latex. (b) Morphology of polymer film that was prepared from PBA(XL)/P (BA-AA) core-shell composite latex. (c) Morphology of the polymer film that was prepared from PBA-PAA copolymer latex.

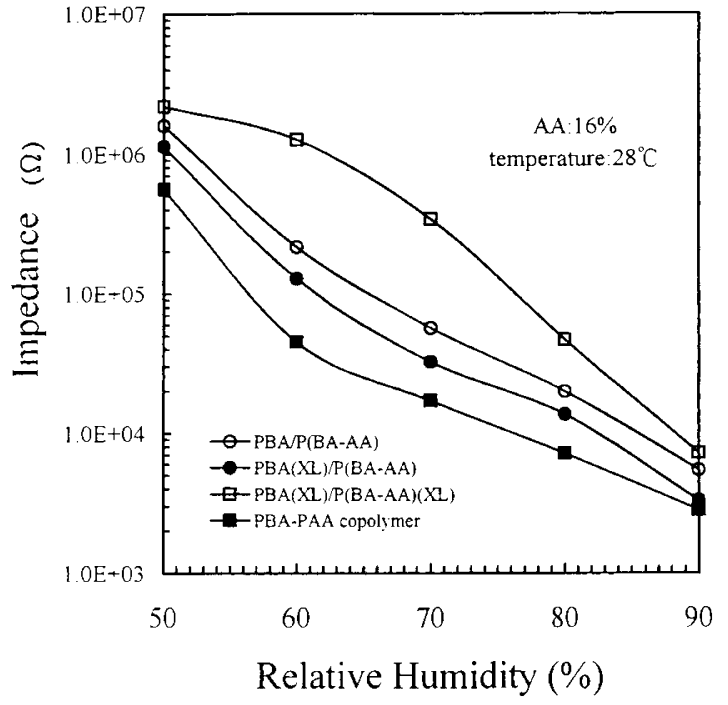

Figure 2. Influence of structure of latex particles on impedance response curve.

melted to form the polymer film, most of the hydrophilic carboxylic acid groups were located on the surface of polymer film. During absorption, a larger amount of
Table I. Effects of structure of latex particles on impedance change (weight fraction of AA in total monomers was $16 \%$ )

\begin{tabular}{lcc}
\hline $\begin{array}{c}\text { Structure of latex } \\
\text { particles }\end{array}$ & $\begin{array}{c}\text { Range of impedance } \\
\text { change } \\
(50 \% \mathrm{RH}-90 \% \mathrm{RH})\end{array}$ & $\begin{array}{c}\text { Impedance ratio } \\
(50 \% \mathrm{RH} / 90 \% \mathrm{RH})\end{array}$ \\
\hline $\mathrm{PBA} / \mathrm{P}(\mathrm{BA}-\mathrm{AA})$ & $1.61 \mathrm{M} \Omega-5.45 \mathrm{~K} \Omega$ & 295.4 \\
\hline $\mathrm{PBA}(\mathrm{XL}) / \mathrm{P}(\mathrm{BA}-\mathrm{AA})$ & $1.13 \mathrm{M} \Omega-3.3 \mathrm{~K} \Omega$ & 342.4 \\
\hline $\mathrm{PBA}(\mathrm{XL}) / \mathrm{P}(\mathrm{BA}-\mathrm{AA})(\mathrm{XL})$ & $2.21 \mathrm{M} \Omega-7.19 \mathrm{~K} \Omega$ & 307.4 \\
\hline $\mathrm{PBA}-\mathrm{PAA}$ copolymer & $561 \mathrm{M} \Omega-2.82 \mathrm{~K} \Omega$ & 198.9
\end{tabular}

The core-shell composite latex with a linear PBA core and $\mathrm{P}$ (BA-AA) copolymer shell was indicated as $\mathrm{PBA} / \mathrm{P}(\mathrm{BA}-\mathrm{AA})$. The core-shell composite latex with a crosslinking PBA core and linear $\mathrm{P}(\mathrm{BA}-\mathrm{AA})$ copolymer shell was indicated as $\mathrm{PBA}(\mathrm{XL}) / \mathrm{P}\left(\mathrm{BA}^{-}\right.$ AA). The core-shell composite latex with a crosslinking PBA core and crosslinking $\mathrm{P}(\mathrm{BA}-\mathrm{AA})$ copolymer shell was indicated as $\mathrm{PBA}$ $(\mathrm{XL}) / \mathrm{P}(\mathrm{BA}-\mathrm{AA})(\mathrm{XL})$

moisture is absorbed on the surface of the polymer film quickly at high humidity. During desorption, moisture escaped from the surface of the polymer film quickly at low humidity. The polymer film prepared by melting the polymer latex with the core-shell structure had the high humidity sensitivity. Most of the carboxylic acid groups merged inside the copolymer latex. Therefore, less hydrophilic functional groups were distributed on the sur- 
Table II. Effects of ratio of hydrophilic to hydrophobic monomer on impedance ratio

\begin{tabular}{ccc}
\hline $\begin{array}{c}\text { Structure of latex } \\
\text { particles }\end{array}$ & $\begin{array}{c}\text { Weight fraction of AA } \\
\text { in total monomers }\end{array}$ & $\begin{array}{c}\text { Impedance ratio } \\
(50 \% \mathrm{RH} / 90 \% \mathrm{RH})\end{array}$ \\
\hline & $\mathrm{AA}: 7.8 \%$ & 48.6 \\
$\mathrm{PBA}$ & $\mathrm{AA}: 12 \%$ & 148.8 \\
\hline & $\mathrm{AA}: 16 \%$ & 295.4 \\
\hline & $\mathrm{AA}: 7.8 \%$ & 29.9 \\
\hline & $\mathrm{AA}: 12 \%$ & 54.2 \\
\hline & $\mathrm{AA}: 16 \%$ & 342.4 \\
\hline & $\mathrm{AA}: 7.8 \%$ & 13.1 \\
\hline & $\mathrm{AA}: 12 \%$ & 47.4 \\
\hline
\end{tabular}

face of the polymer film prepared by melting the copolymer latex. So, less moisture could be adsorbed on the film's surface during the absorption process at high humidity. Moreover, water molecules were absorbed into the polymer film by the carboxylic acid that merged inside the polymer film. The water molecular was not easy to quickly remove during desorption at low humidity. The polymer film thus had the low humidity sensitivity. Table I shows that the core-shell polymer latex with crosslinking core has the best humidity sensitivity, and the impedance ratio of $50 \% \mathrm{RH} / 90 \% \mathrm{RH}$ is 342.4 times. The reason was that the PAA phase in the polymer films with the crosslinked structure was not disrupted easily by water, so the films with crosslinked structure possessed the best water resistivity and humidity sensitivity.

\section{Ratio of Hydrophilic to Hydrophobic Monomer}

The effect of the ratio of hydrophilic to hydrophobic monomer on the impedance showed that the more the hydrophilic functional groups, the lower the impedance. This suggests that with more hydrophilic functional groups, the dissociation of ions $\left(\mathrm{Na}^{+}\right)$is much more possible, and the mobility of ions (e.g., $\mathrm{Na}^{+}$) increases due to the absorption of many more water vapor molecules at higher relative humidity. The results were the same as our previous study in the PMMA/P(MMA-MAA) humidity sensitive polymer films. ${ }^{17}$ The impedance ratio $(50 \%$ $\mathrm{RH} / 90 \% \mathrm{RH}$ ) is shown in Table II, which showed that had nothing to do with the structure of latex particle, the more the hydrophilic functional groups, the larger the impedance ratio. So, that the humidity sensitivity of the polymer films increase with increasing the amount of hydrophilic functional groups.

\section{Effect of Multiple Use of Polymer Film on the Humidity Sensitivity}

Figure 3 shows the effect of multiple use of the polymer films produced by melting the core-shell polymer latex with linear structure on the humidity sensitivity. There was no obvious change in humidity sensitivity after multiple use of the polymer films below $80 \%$ relative humidity, but at $90 \%$ relative humidity, the effect of multiple use of the polymer films on the humidity sensitivity was significant. The reason was because that at the higher relative humidity, the more water molecular was adsorpted on the PAA phase of the polymer films

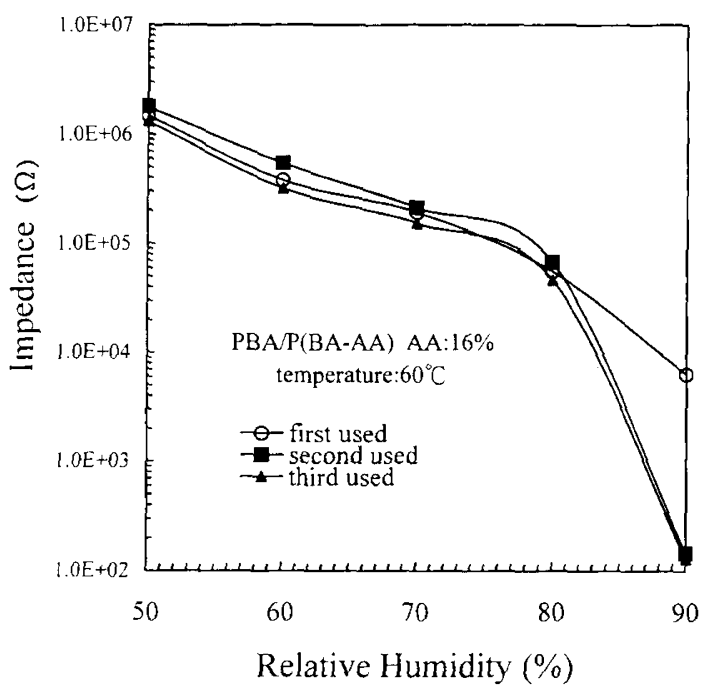

Figure 3. Comparison of response curves after multiple use of the humidity-sensitive polymer film formed from melting the latex polymer with linear structure synthesized through soapless seeded emulsion polymerization.

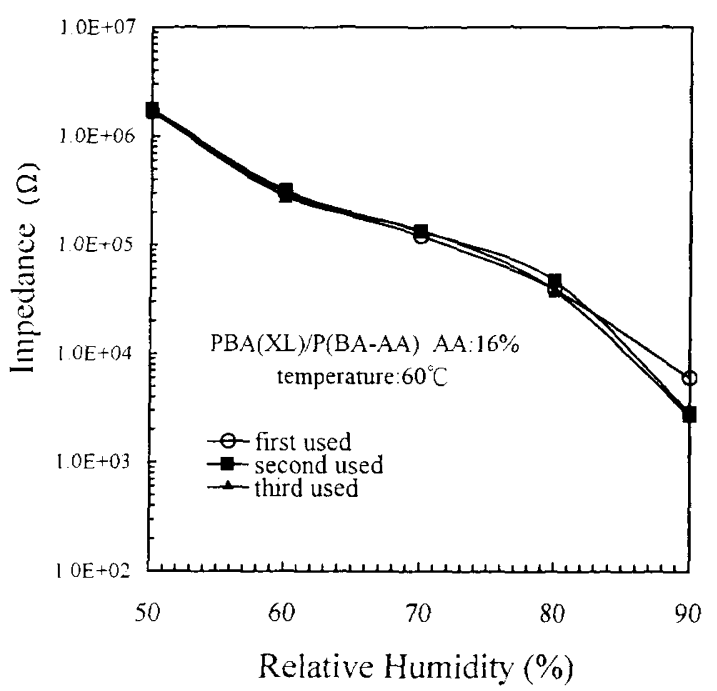

Figure 4. Comparison of response curves after multiple use of the humidity-sensitive polymer film formed from melting the latex polymers with crosslinking core synthesized through soapless seeded emulsion polymerization.

due to hydrophilic property. The structure of the PAA phase was partially dissolved by the water molecular. On the other hand, after the polymer films were multiple use, the change in sensitivity of polymer films produced by melting the core-shell polymer latex with crosslinked core was insignificant as shown in Figure 4, since the polymer films melted from the crosslinked core -shell polymer latex had the best water resistivity. Hence there was no obvious change in sensitivity after multiple use of the polymer films.

\section{Temperature Effect}

The effect of temperature on the humidity sensitivity of polymer films produced by melting the linear coreshell polymer latex is shown in Table III. The impedance ratio $(50 \% \mathrm{RH} / 90 \% \mathrm{RH})$ decreased with increase in temperature. That is, the humidity sensitivity decreased 
Table III. Effects of temperature on impedance change

\begin{tabular}{ccc}
\hline $\begin{array}{c}\text { Structure of latex } \\
\text { particles }\end{array}$ & Temperature & $\begin{array}{c}\text { Impedance ratio } \\
(50 \% \mathrm{RH} / 90 \% \mathrm{RH})\end{array}$ \\
\hline & $28^{\circ} \mathrm{C}$ & 295.4 \\
\cline { 2 - 3 } $\begin{array}{c}\text { PBA/P(BA-AA) } \\
(\mathrm{AA}: 16 \%)\end{array}$ & $40^{\circ} \mathrm{C}$ & 309.4 \\
\cline { 2 - 3 } & $60^{\circ} \mathrm{C}$ & 194.1 \\
\cline { 2 - 3 } PBA/P(BA-AA) & $28^{\circ} \mathrm{C}$ & 148.8 \\
\cline { 2 - 3 }$(\mathrm{AA}: 12 \%)$ & $40^{\circ} \mathrm{C}$ & 70.3 \\
\hline & $60^{\circ} \mathrm{C}$ & 64.6 \\
\hline & $28^{\circ} \mathrm{C}$ & 54.2 \\
\hline PBA(XL)/P(BA-AA) & $40^{\circ} \mathrm{C}$ & 80.6 \\
\cline { 2 - 3 }$(\mathrm{AA}: 16 \%)$ & $60^{\circ} \mathrm{C}$ & 80.5 \\
\hline & $28^{\circ} \mathrm{C}$ & 198.9 \\
\hline PBA-PAA copolymer & $40^{\circ} \mathrm{C}$ & 52.9 \\
\cline { 2 - 3 }$(\mathrm{AA}: 16 \%)$ & $60^{\circ} \mathrm{C}$ & 44.1 \\
\hline
\end{tabular}

with an increase in temperature, which was different from that in poor flexible polymer films ${ }^{17}\left(T_{\mathrm{g}} 130.1^{\circ} \mathrm{C}\right)$. In flexible films produced by melting the PBA/P(BA-AA) polymer latex $\left(T_{\mathrm{g}}-34.8^{\circ} \mathrm{C}\right)$, the migration of the charge carrier was easy even at low temperature due to the flexible polymer chains. So, temperature was not the domineering factor. In less flexible films produced by melting the $\mathrm{PBA}(\mathrm{XL}) / \mathrm{P}(\mathrm{BA}-\mathrm{AA})$ polymer latex $\left(T_{\mathrm{g}}-15.2^{\circ} \mathrm{C}\right)$ with crosslinked core, the effect of high temperature increased the water intake of the films and enhanced the mobility of the charge carrier. So, increase in temperature would increase the humidity sensitivity of less flexible films produced by melting the core-shell polymer latex with crosslinking seed, as seen in Table III. The temperature effect on the humidity sensitivity of the polymer films produced by melting the linear copolymer latex is shown in Table III. Similar to the linear core--shell latex films, the impedance ratio decreased with increase in temperature as expected for flexible films.

\section{Hysteresis}

At $28^{\circ} \mathrm{C}$, the humidity-sensitive polymer films produced by melting the core-shell polymer latex with crosslinking core had little hysteresis as shown in Figure 5 . The polymer films produced by melting core-shell polymer latex with linear core had little hysteresis too. Since most of the hydrophilic carboxylic acid groups were located on the surface of core-shell polymer latex, so most of the hydrophilic carboxylic acid groups were located on the surface of the polymer films prepared from the core-shell polymer latex. Absorption and desorption were thus quicker. Contrary to the core-shell polymer latex, the hydrophilic carboxylic acid groups of the copolymer latex often merged inside the latex particles, so there were fewer hydrophilic carboxylic acid groups on the surface of polymer films prepared from the copolymer latex. Therefore, at high humidity, water molecules permeating through and accumulated inside the polymer films during the entire absorption process. At low humidity, the water molecular was not easy to quickly remove from polymer film. So that the hysteresis of polymer films prepared from the copolymer latex was more significant. Large hysteresis was observed for polymer film prepared from the copolymer latex as shown in Fig-

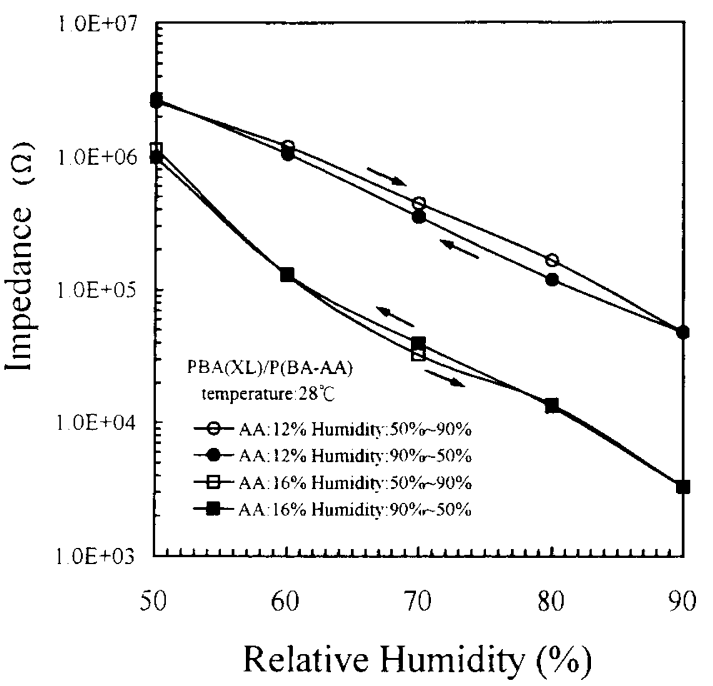

Figure 5. Hysteresis behavior of humidity-sensitive polymer film formed from melting the core-shell latex polymers with crosslinking core synthesized through soapless seeded emulsion polymerization.

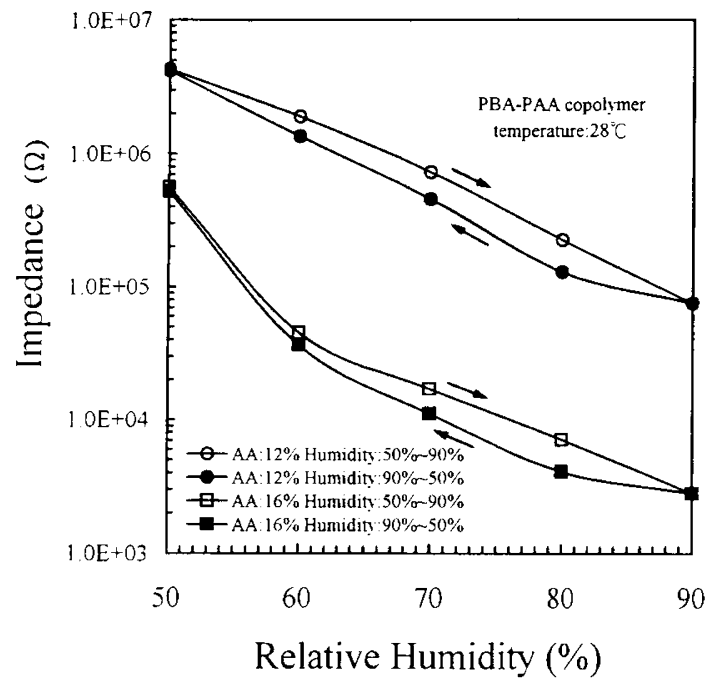

Figure 6. Hysteresis behavior of humidity-sensitive polymer film formed from melting the linear copolymer latex synthesized through soapless emulsion copolymerization.

ure 6.

\section{Effect of Components in Polymer Films}

The humidity sensitivity of the polymer films was influenced by the components of the latex shown as Figure 7. The polymer films produced by melting the PBA/P (BA-AA) core-shell latex with PBA core and P(BA-AA) copolymer shell had higher humidity sensitivity than polymer films made by melting the PMMA/P(MMA-AA) core-shell latex with PMMA core and P(MMA-AA) copolymer shell. At relative humidity $50-90 \%$, the impedance ratio $50 \% \mathrm{RH} / 90 \% \mathrm{RH}$ of $\mathrm{PBA} / \mathrm{P}(\mathrm{BA}-\mathrm{AA})$ polymer films was 148.9 and the impedance ratio $50 \% \mathrm{RH} / 90 \%$ RH of PMMA/P(MMA-AA) polymer films was 30 . The humidity sensitivity of the former was thus higher than the latter, since PBA polymer chains were more flexible than the PMMA polymer chains. The humidity response of PBA was quicker than PMMA, and the humidity sen- 


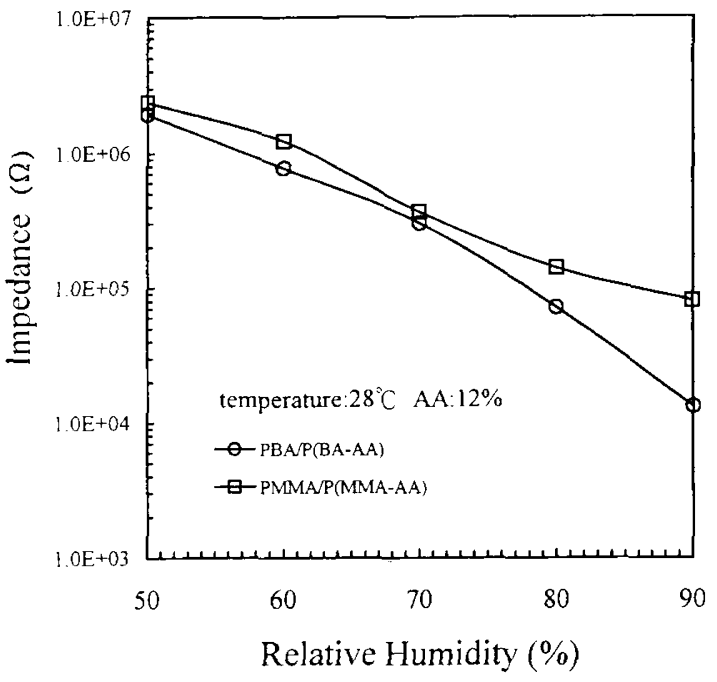

Figure 7. Component effects on response curve of the humiditysensitive polymer film formed from melting the latex polymers synthesized through soapless seeded emulsion polymerization with $12 \%$ AA.

sitivity of the $\mathrm{PBA} / \mathrm{P}(\mathrm{BA}-\mathrm{AA})$ polymer films was larger than PMMA/P(MMA-AA) polymer films.

\section{CONCLUSION}

The polymer films prepared from the $\mathrm{PBA}(\mathrm{XL}) / \mathrm{P}(\mathrm{BA}-$ AA) core-shell polymer latex with crosslinked core had better humidity sensitivity and less hysteresis than those prepared from the $\mathrm{PBA} / \mathrm{P}(\mathrm{BA}-\mathrm{AA})$ core-shell polymer latex with linear core. The humidity sensitivity of the polymer films increased, with an increase of hydrophilic functional groups. After the polymer films were multiple used, the polymer films with crosslinked structure retained the same humidity sensitivity. Increase of the temperature may increase the humidity sensitivity of the poor flexible polymer films. But the reverse effect appeared in the flexible polymer films prepared from the linear core-shell polymer latex $\mathrm{PBA} / \mathrm{P}(\mathrm{BA}-\mathrm{AA})$ or copolymer latex $\mathrm{P}(\mathrm{BA}-\mathrm{AA})$. With improved flexibility, $\mathrm{PBA} / \mathrm{P}(\mathrm{BA}-\mathrm{AA})$ polymer films had larger humidity sensitivity than PMMA/P(MMA-AA) polymer films.

\section{REFERENCES}

1. N. Yamazoe and Y. Shimizu, Sensors and Actuators, 10, 379 (1986).

2. B. M. Kulwicki, J. Am. Ceram. Soc., 74, 697 (1991).

3. M. Hijikigawa, S. Miyoshi, T. Sugihara, and A. Jinda, Sensors and Actuators, 4, 307 (1983).

4. N. Kinjo, O. Ohara, T. Sugawara, and T. Tsuchitani, Polym. J., 15, 621 (1983).

5. Y. Takaoka, Y. Maebashi, S. Kobayashi, and T. Usui, Japan Tokkyo Koho (patent) 58, (1983).

6. Y. Sadaoka, Y. Sakai, Denki Kagaku, 52, 132 (1984).

7. Y. Sakai, Y. Sadaoka, H. Omura, and N. Watanabe, Kobunshi Ronbunshu, 41, 205 (1984).

8. Y. Sakai, Y. Sadaoka, H. Omura, and N. Watanabe, Kobunshi Ronbunshu, 41, 209 (1984).

9. Y. Sadaoka and Y. Sakai, Denki Kagaku, 53, 150 (1985).

10. Y. Sadaoka, Y. Sakai, and H. Akiyama, J. Mater. Sci., 21, 235 (1986).

11. Y. Sadaoka and Y. Sakai, J. Mater. Sci. Lett., 5, 772 (1986).

12. Y. Sakai, Y. Sadaoka, and K. Ikeuchi, Sensors and Actuators, 9, 125 (1986).

13. Y. Sakai, Y. Sadaoka, and H. Fukumoto, Sensors and Actuators, 13, 243 (1986).

14. Y. Sakai, Y. Sadaoka, and M. Matsuguchi, J. Electrochem. Soc., 136, 171 (1989).

15. H. Shirakawa, E. J. Louis, A. G. Macdiarmid, C. K. Chang, and A. J. Heeger, J. Chem. Soc., Chem. Commum., 578 (1977).

16. Y. Sakai, M. Masanobu, Y. Sadaoka, and H. Kazuko, J. Electrochem. Soc., 140 (1993).

17. S. C. Hsu, C. F. Lee, and W. Y. Chiu, J. Appl. Polym. Sci., 71, 47 (1999).

18. C. F. Lee, W. Y. Chiu, and Y. C. Chern, J. Appl. Polym. Sci., 57, $591(1995)$

19. C. F. Lee, K. R. Lin, and W. Y. Chiu, J. Appl. Polym. Sci., 51, $1621(1994)$

20. C. F. Lee and W. Y. Chiu, J. Appl. Polym. Sci., 56, 1263 (1995).

21. C. F. Lee and W. Y. Chiu, J. Appl. Polym. Sci., 57, 591 (1995).

22. C. F. Lee and W. Y. Chiu, J. Appl. Polym. Sci., 65, 425 (1997). 